
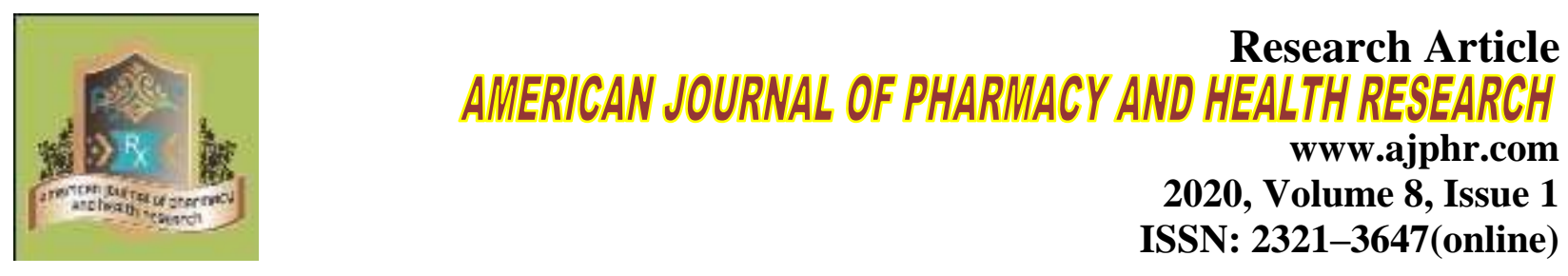

\title{
Optimization and Characterization of Herbal Hand Sanitizer by Using Drug Parsley
}

\author{
D. N. Hagir*, K.V.Otari, P.P. Surushe \\ NES'S Navsahyadri Institute of Pharmacy, Naigaon, Nasarapur, Pune-412 213, India
}

\begin{abstract}
Sanitizer are available in market, but contain chemical, that's why they give side effects. So, attempt to prepare herbal hand sanitizer. Herbal hand sanitizer are used to show antimicrobial activity against, viruses, fungi, pathogens, and (bacteria - E.coli, pseudomonas aeuroginosa, staphylococcus aureus, and Bacillus subtilis). Herbal sanitizer prepared from herbal drugs. So it's having no side effects as compared to standard. Using medicinal herb and plant with human has been known since the old civilization. Old drug industry depend on raw materials of medicinal herbs and plant and their extract, which always proved safe. Herbal formulation is always use as protective purpose by micro-organisms such kind of this formulation is helpful to protect from bacteria and virus and it's should have capacity to kill micro-organism, bacteria, viruses, fungi etc ${ }^{1}$.
\end{abstract}

Keywords: Sanitizer, Parsley, Microorganism, Herbal drug, Zone of inhibition, E. coli. 


\section{INTRODUCTION}

Hygiene is defined as maintenance of cleanliness practices which carries importance in maintenance of health. Keeping bodily hygiene usage of cleansers are requisites of healthy living. This concept highlight the need of maintaining hygiene in prevention of diseases. $[5,6]$ Although good \& simple hygiene technique is single most important, easy and least expensive means of preventing health care-associated (nosocomial) infections and the spread of antimicrobial multidrug resistance but unfortunately poor hand-hygiene practices are still observed due to lack of scientific knowledge, unawareness of risks and unavailability of hand hygiene facilities. [1,2] Nosocomial infections are those which acquired or originated in a hospital or health care setting and are result of high prevalence of pathogens, high prevalence of compromised host's efficient mechanisms of transmission from patient to patient. Thus occurrence of nosocomial infections is alarmingly increasing and has emerged as a serious concern in hospital care outcome resulting in prolonged hospitalization, ample disease and mortality, and excessive costs. Escherichia coli, Pseudomonas species and Staphylococcus aureus are commonly involved opportunistic microorganisms that primarily cause nosocomial infections.

Generally infectious sites are urinary tract, surgical wounds, respiratory tract, skin, blood, gastrointestinal tract, and central nervous system. These pathogens also tend to become incorporated into the normal flora of health care workers.

Pseudomonas Aeruginosa is the most commonly detected microorganism in hospitalized patients and immune suppressed people. Opportunistic fungal infections have become very important especially in HIV patients and the highest frequencies of opportunistic fungal infections documented are candidiasis, aspergillosis and cryptococcosis. [6,7] Usually, microbes residing on the hands are divided into resident and transient flora. Resident flora (e.g. Coryne bacterium diphtheriae, Staphylococcus aureus, Staphylococcus epidermidis and Streptococcus viridians) colonizing deeper skin layers are more resistant to mechanical removal has lower pathogenic potential. Transient flora (e.g. Staphylococcus aureus, Gram-negative bacilli, Candida species) colonizes the superficial skin layers for short periods, is usually acquired by contact with a patient or contaminated environment and these microorganisms are easily removed by mechanical means such as hand washing and are responsible for most health care-associated infections and the spread of antimicrobial resistance. In the current scenario of mechanized life style a consumer will always prefer ready-made formulation of alcohol hand rub rather than hand washing (application of a non-antimicrobial or antimicrobial soap and mechanical friction is 
generated by rubbing the hands together for 1 minute, followed by rinsing with water, and then drying thoroughly with a disposable towel. Traditional healers have long used plants to prevent or cure infectious conditions. Plants are rich in a wide variety of secondary metabolites, such as tannins, terpenoids, alkaloids, and flavonoids, which have been found in vitro to have antimicrobial properties. [7,10] Considering this ultimatum an attempt has been made to screen classical literature for the herbs with antimicrobial properties and found that, Parsley (petroselinum) has those antimicrobial activities. To formulate and evaluate herbal sanitizer comprise of combination of alcoholic extracts of Parsley, using suitable excipients which can be used as a ready-made herbal hand sanitizer.

A microorganism or microbe is a microscopic organism, which may be single-celled ${ }^{[1]}$ or multicellular. The study of microorganisms is called microbiology, a subject that began with the discovery of microorganisms in 1674 by Antonie van Leeuwenhoek, using a microscope of his own design.

Microorganisms are very diverse and include all bacteria, archaea and most protozoa. This group also contains some fungi, algae, and some micro-animals such as rotifers. Many macroscopic animals and plants have microscopic juvenile stages. Some microbiologists classify viruses and viroids as microorganisms, but others consider these as nonliving. ${ }^{[2][3]}$ In July 2016, scientists identified a set of 355 genes from the last universal common ancestor of all life, including microorganisms, living on Earth.

\section{Diseases caused due to microbes}

\section{Bacterial diseases}

- Anthrax

- Botulism

- Cholera

- Chlamydiasis (new)

- Dental Caries (tooth decay)

- Legionnaire's Disease
- Pertussis (whooping cough)

- Rocky Mountain spotted fever

- Strep throat

- Syphilis

- Tetanus

- Tuberculosis

\section{Poor sanitization}

Human excreta have been implicated in the transmission of many infectious diseases including cholera, typhoid, infectious hepatitis, polio, cryptosporidiosis, and ascariasis. Undernutrition, pneumonia, worm infestations, are also associated with unsafe water, poor sanitation and hygiene resulting in reduced physical growth, weakened physical fitness and impaired cognitive function, particularly for children under the age of five. 
Infectious agents are not the only health concerns associated with wastewater and excreta. Heavy metals, toxic organic and inorganic substances also can pose serious threats to human health and the environment - particularly when industrial wastes are added to the waste stream. [15]

For that measure attempt to prepare hand sanitizer by using natural drug Parsley, so that minimizes the side effects of synthetic hand sanitizer. Also evaluate by using antimicrobial activity and compare with standard formulation by taking zone of inhibition.

\section{MATERIALS AND METHOD}

\section{Drugs and Chemicals}

Leaves of Parsley (petroselinum) was collected from local area of Satara region. Nutrient Agar for bacterial cultivation, standard hand sanitizer were purchased from market, Culture of microorganisms (overnight incubated), Alcohol were of lab grade. Pathogens selected for evaluation of anti-microbial activity of the test drug were specified below.

Parsley (Petroselinum crispum) is a herbs commonly used to flavor the cuisines of china, Mexico, South America, India and South East Asia .Parsley is native to Europe and western Asia and cultivated in the united states as an annual for its aromatic and attractive leaves. Components of fresh parsley leaf scavenge superoxide anion in vitro, and methanol extracts of parsley scavenge hydroxyl radical in addition to protecting against ascorbic acid induced membrane oxidation. Supplementation of diets with fresh leaf can increase antioxidant capacity of rat plasma and decrease the oxidative stress in humans.

\section{Botanical name}

Petroselinum crispum, mill fuss

\section{Synonyms}

\section{Apium crispum}

Apium petroselinum $L$.

Petroselinum hortense Hoffm.

Petroselinum sativum Hoffm.

Garden parsley is a bright green, biennial, plant in temperate climates, or an annual herb in subtropical and tropical areas. [15]

Where it grows as a biennial, in the first year, it forms a rosette of tripinnate leaves $10-25 \mathrm{~cm}$ long with numerous 1-3 cm leaflets, and a taproot used as a food store over the winter. In the second year, it grows a flowering stem to $75 \mathrm{~cm}$ (30 in) tall with sparser leaves and flat-topped $3-10 \mathrm{~cm}$ diameter umbels with numerous $2 \mathrm{~mm}$ diameter yellow to yellowish-green flowers. The 
seeds are ovoid, 2-3 mm long, with prominent style remnants at the apex. One of the compounds of the essential oil is apiol. The plant normally dies after seed maturation.

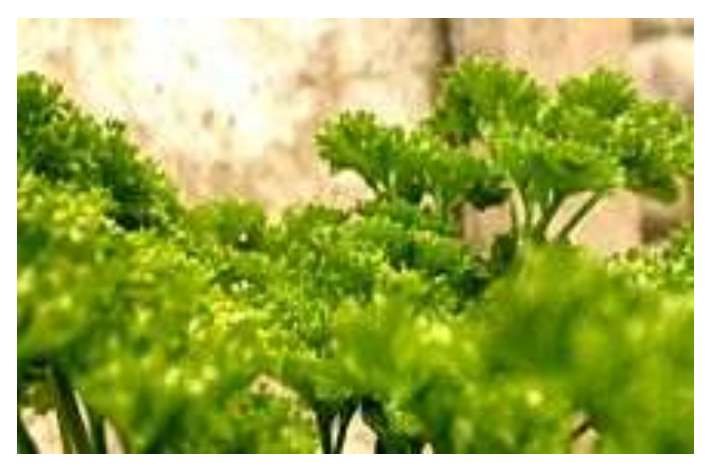

Figure 1: Parseley

\section{Bacterial strains:}

1. Escherichia coli (gram-ve)

2. Staphylococcus aureus (gram +ve)

\section{Ingredients and excipients used:}

Deionized water, alcohol, parseley leaves extract, carbopol 940, triethanolamine, glycerine, polysorbate 20, perfume and preservative.

\section{Extraction of plant material:}

\section{Hot Continuous Extraction (Soxhlet)}

In this method, the finely ground crude drug is placed in a porous bag or "thimble" made of strong filter paper, which is placed in chamber of the Soxhlet apparatus (Figure 2). The extracting solvent in flask is heated, and its vapors condense in condenser. [5, 6] The condensed extractant drips into the thimble containing the crude drug, and extracts it by contact. When the level of liquid in chamber rises to the top of siphon tube, the liquid contents of chamber siphon into flask. This process is continuous and is carried out until a drop of solvent from the siphon tube does not leave residue when evaporated. The advantage of this method, compared to previously described methods, is that large amounts of drug can be extracted with a much smaller quantity of solvent. This effects tremendous economy in terms of time, energy and consequently financial inputs. At small scale, it is employed as a batch process only, but it becomes much more economical and viable when converted into a continuous extraction procedure on medium or large scale. 


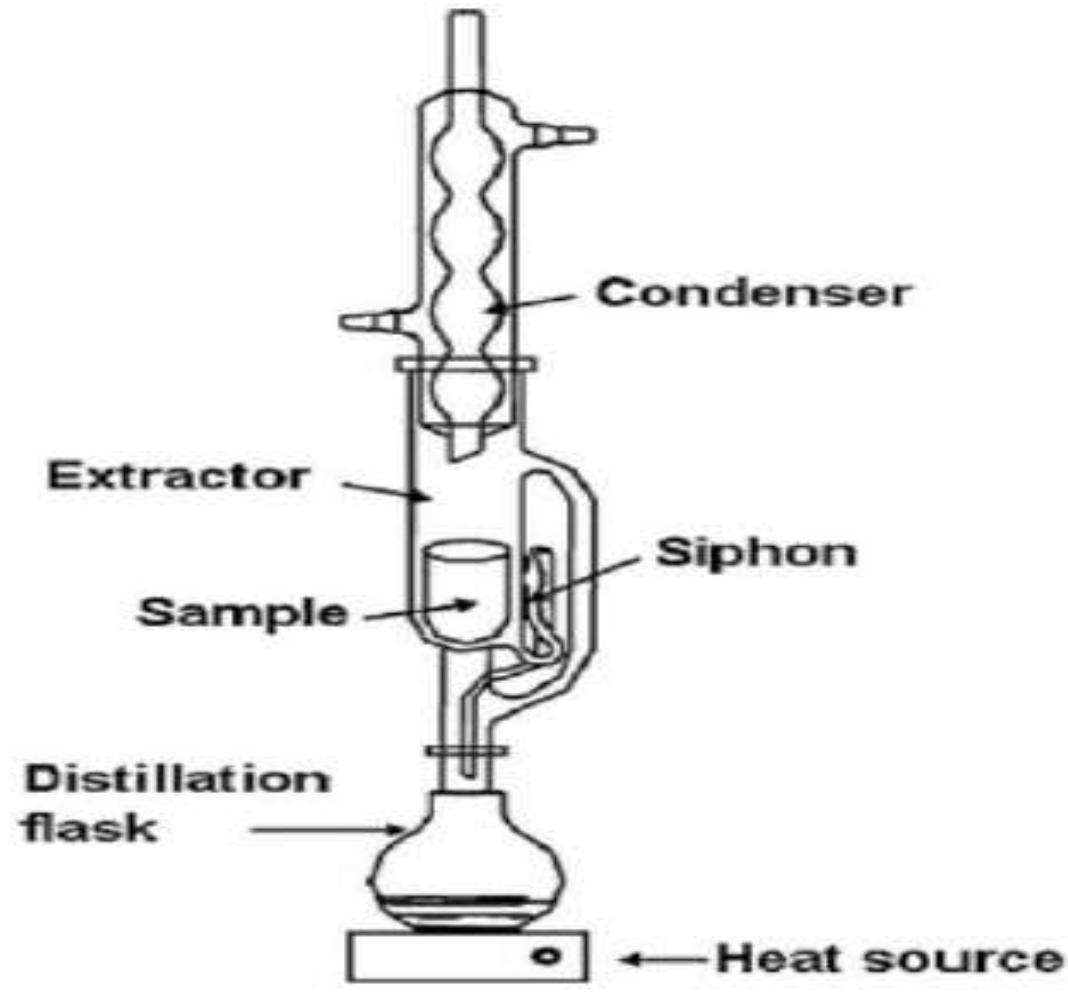

Figure 2: Soxhlet Apparatus

\section{FORMULATION OF HERBAL HAND SANITIZER:}

Carbopol was added to deionized water with constant stirring. After uniform mixing, Tri Ethanol Amine (TEA) was added with slow stirring to avoid formation of possible air bubbles in the product and kept aside for $24 \mathrm{hrs}$. All the extracts were added to denatured alcohol along with glycerin, polysorbate 20 were mixed with aqueous phase. Finally, $0.25 \%$ each of Methyl \& Propyl Paraben was added as preservative and $0.5 \%$ of perfume and mixed with slow stirring to obtain uniform product. Prepared product was stored in air tight HDPE containers. [13]

\section{Table 1: Formulation composition of Herbal Hand Sanitizer}

\begin{tabular}{lll}
\hline Sr. No. & Ingredients and Excipients & Quantity \\
\hline 1 & Deionized water & $9.3 \mathrm{ml}$ \\
2 & Alcohol & $18.6 \mathrm{ml}$ \\
3 & Parseley leaves extract & $0.03 \mathrm{ml}$ \\
4 & Carbopol 940 & $0.15 \mathrm{gm}$ \\
5 & Tri Ethanol Amine & $0.21 \mathrm{ml}$ \\
6 & Glycerin & $0.69 \mathrm{ml}$ \\
7 & Polysorbate 20 & $0.15 \mathrm{gm}$ \\
8 & Perfume & $0.15 \mathrm{ml}$ \\
9 & Preservative & $0.15 \mathrm{gm}$ \\
\hline
\end{tabular}




\section{RESULTS AND DISCUSSION}

Total two bacterial species were selected in a presence of study to evaluate antibacterial activity of the test drug at different concentration of product were incubated and observed on zone of inhibition. [12,13] The formulation was mixed and antibacterial activity is carried out by counting the zone of inhibition. Nutrient - Agar medium at 5\% concentration was observed in two bacterial species zone of inhibition that is slightly greater in prepared formulated as compare to marketed formulation. These indicate that antimicrobial activity of Parasley sanitizer is slightly greater than marketed formulation.

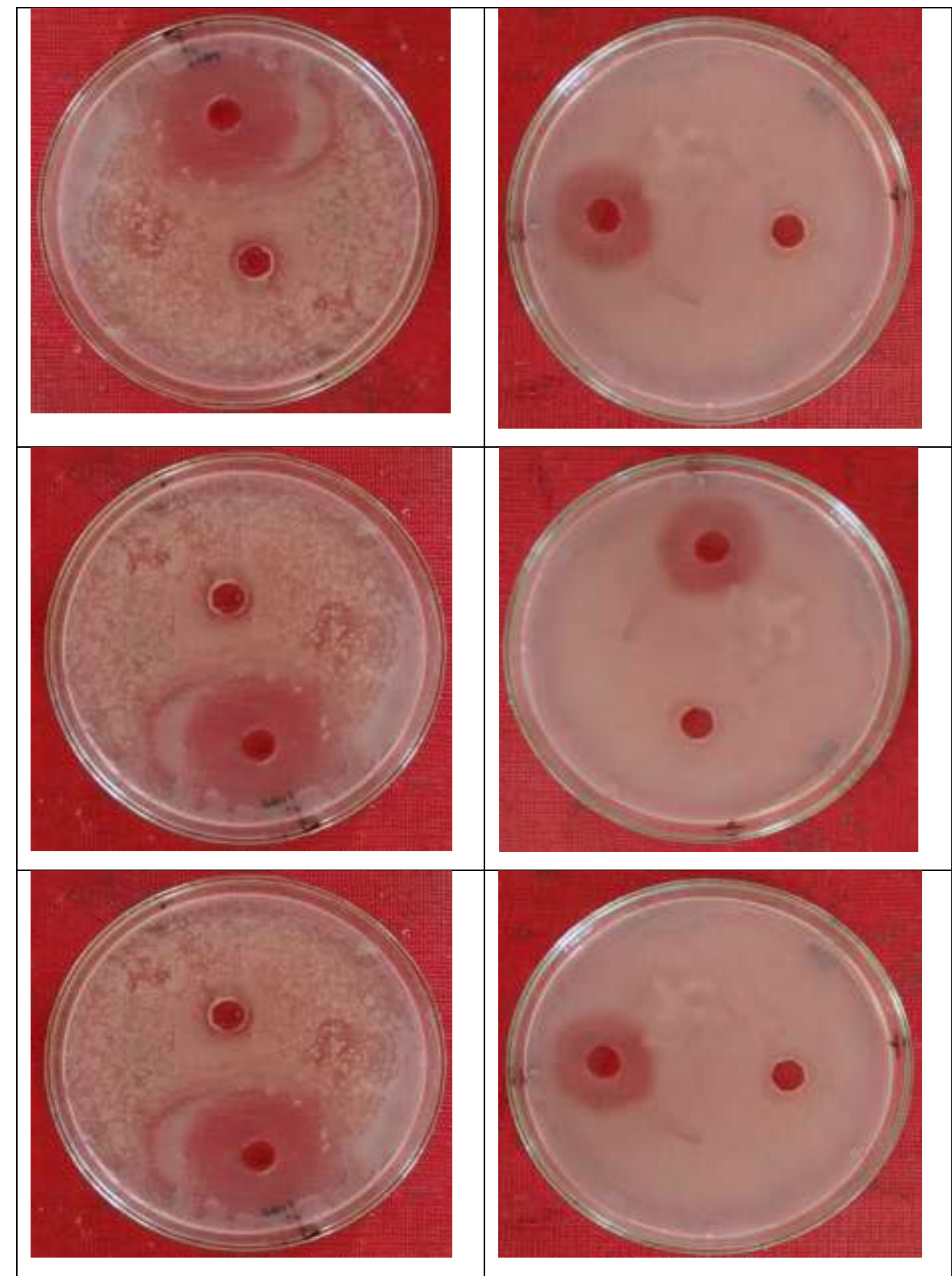

Figure 3: Result of antibacterial study of hand sanitizer against E. coli and staphylococcus aureus 
Table 2: Result of antibacterial study of hand sanitizer (mean + SD)

\begin{tabular}{|c|c|c|c|c|}
\hline \multirow[t]{2}{*}{ Organism } & \multicolumn{4}{|c|}{ Zone of inhibition(mm) } \\
\hline & \multicolumn{2}{|c|}{ Sanitizer formulation } & \multicolumn{2}{|c|}{ standard formulation } \\
\hline \multirow[t]{3}{*}{ E.coli } & 15 & $14 \pm 2.6$ & 12 & $13.7 \pm 1.5$ \\
\hline & 16 & & 14 & \\
\hline & 11 & & 15 & \\
\hline \multirow[t]{3}{*}{ Staphylococcus aureus } & 14 & $14 \pm 2$ & 12 & $13.3 \pm 1.5$ \\
\hline & 12 & & 13 & \\
\hline & 16 & & 15 & \\
\hline
\end{tabular}

(Where: $\mathrm{mm}=$ millimeter)

\section{DISCUSSION}

The prepared formulation of herbal hand sanitizer is showed significant result at concentration against two bacterial species. Zone of inhibition is greater in herbal hand sanitizer as compare to marketed preparation. More concentration is needed for broad spectrum activity.

\section{CONCLUSION}

It may be concluded that Herbal hand sanitizer has a significant antibacterial effect on the specified bacteria. Thus there is immense potential in establishing the case of antibacterial Herbal products as measure to control resistant bacteria. As it is natural substance, it gives less side effects as compare to synthetic formulation.

\section{ACKNOWLEDGEMENT}

It is a great pleasure to admit the contribution of the individuals who extended their helping hand during my research work, which enabled me to accomplish the work in time. I must say that without their support it would not have been so easy. I express my deep gratitude towards respected Sir Dr. K.V. Otari (Principal, Navsahyadri Institute of pharmacy, Naigaon, Pune) for helpful discussion unfailing advice, right way to do work confidently and constant encouragement during the project work.

\section{REFERENCES}

1. PalaK .V. Yas et al. Antimicrobial Activity of Ayurvedic Hand Sanitizers. International Journal of Pharmaceutical \& Biological Archives. 2011; 2(2):762-766.

2. Larson E. Skin hygiene and infection prevention: More of the same or different approaches Infect. Dis. 1999; 29: 1287-1294

3. Burke JP. Patient safety: infection control-a problem for patient safety. N Engl. J. Med. 2003; 348: 651-656.

4. Black J.G. Microbiology: Principles and Applications. 3rd Edition, Prentice Hall, Upper Saddle River, New Jersey. 1996; 436-443. 
5. Widmer AF. Replace hand washing with use of a waterless alcohol hand rub? Clin Infect 2000;31: 136-143.

6. Cowan . M. M, Plant Products as Antimicrobial Agents. Clinical Micro. Reviews. 1999;12(4):564 -82.

7. WHO Guidelines on Hand Hygiene in Health Care (Advanced Draft).

8. Mondal Sunanda, Kolhapure S.A., Evaluation of the antimicrobial efficacy and safety of Pure Hands herbal hand sanitizer in hand hygiene and on inanimate objects. The Antiseptic. 2004;101(3): 112-120.

9. Rotter ML. Hand washing and hand disinfection. In: Hospital Epidemiology and Infection Control,May hall CG, 2nd edition, Philadelphia, Pa: Lippincott Williams \& Wilkins, 1999: 1339-1355.

10. Pittet D, Mourouga P, Perneger TV. Compliance with hand washing in a teaching hospital: infection control program. Ann. Intern. Med. 1999; 130: 126-130.

11. Wani NS, Bhalerao AK, Ranaware VP, et al "Formulation and evaluation of herbal sanitizer.” International Journal of PharmTech Research, 2013, Vol. 5, No. 1, 40-43.

12. Karteek P, Keerthi DV, Sravanthi KC, et al "Evaluation of antibacterial activity of herbs.” International Research Journal of Pharmacy, 2012, 3(8), 230-232.

13. Shah MA, Natarajan SB, et al "Formulation, evaluation and antibacterial efficiency of herbal hand wash gel.” Int.J. Pharm. Sci. Rev. Res., 2014, 25(2), 120-124.

14. Joy JM, Mohanalakshmi S, et al "Formulation and Evaluation of Poly Herbal Hand Wash.” International Journal Of Pharmacy, 2012;2(2), 39- 43.

15. www.wikepedia.com 